\title{
Neoadjuvant Therapy - What Have We Achieved in the Last 20 Years?
}

\author{
Jens Huober ${ }^{\mathrm{a}}$ Gunter von Minckwitz \\ ${ }^{a}$ Breast Center, Kantonsspital St. Gallen, Switzerland \\ ${ }^{\mathrm{b}}$ German Breast Group, Neu-Isenburg, Germany
}

\section{Keywords}

Neoadjuvant chemotherapy · Pathologic complete remission - Molecular subtypes · HER2-positive breast cancer

\section{Summary}

Neoadjuvant chemotherapy is the standard of care for patients with large, inoperable tumors or inflammatory breast cancer, but it is also increasingly considered for women with operable disease. Several randomized trials have demonstrated that anthracycline- and taxane-containing regimens in operable breast cancer were equally effective in terms of disease-free or overall survival regardless of whether they were administered postoperatively or preoperatively. Further neoadjuvant treatment allows for a higher rate of breast conserving surgery. Tumor responses in terms of pathologic complete remission after short-term chemotherapy will probably only serve as a surrogate marker for long-term outcome in some molecular breast cancer subtypes like the triplenegative, HER2-positive, and some luminal B subsets. Recent trials showed that in HER2-positive disease pCR rates were as high as $70 \%$ when 2 HER2-targeted agents were added to chemotherapy.

\section{Introduction}

Neoadjuvant therapy is defined as the first systemic treatment a patients receives when non-metastatic breast cancer is diagnosed. Neoadjuvant treatment has the ability to shrink tumors and was first used in patients with inoperable locally advanced or inflammatory disease. Data from several retrospective analyses showed that the application of multimodal treatment consisting of neoadjuvant chemotherapy, surgery, radiother-

\author{
Schlüsselwörter \\ Neoadjuvante Chemotherapie - Pathologisch komplette \\ Remission · Molekulare Subtypen · HER2-positives \\ Mammakarzinom
}

\section{Zusammenfassung}

Eine neoadjuvante Chemotherapie ist die Standardtherapie bei Patientinnen mit lokal fortgeschrittenen inoperablen oder inflammatorischen Mammakarzinomen. Heutzutage wird eine neoadjuvante Behandlung jedoch auch zunehmend häufiger bei Frauen mit gut operablen Tumoren eingesetzt. Mehrere Studien haben gezeigt, dass anthrazyklin- und taxanhaltige Regime - unabhängig davon, ob vor oder nach der Operation verabreicht gleich effektiv hinsichtlich des erkrankungsfreien Überlebens und des Gesamtüberlebens waren. Allerdings konnte nach neoadjuvanter Therapie die Rate der brusterhaltenden Operationen gesteigert werden. Das Tumoransprechen im Sinne einer pathologisch kompletten Remission nach neoadjuvanter Chemotherapie ist wahrscheinlich nur bei bestimmten molekularen Subtypen wie tripel-negativen, HER2-positiven und einigen Luminal-B-Tumoren ein Surrogatmarker für den langfristigen Krankheitsverlauf. Bei Patientinnen mit HER2-positivem Mammakarzinom erreichten in einer kürzlich berichteten Studie durch die Addition von 2 anti-HER2-Substanzen zur Chemotherapie die pCR-Raten bis zu 70\%.

apy, and hormonal therapy improved survival for patients with these poor-prognosis tumors [1]. In the NOAH study in patients with locally advanced and inflammatory tumors overexpressing the human epidermal growth factor receptor 2 (HER2), the addition of trastuzumab to standard preoperative chemotherapy significantly improved the pathologic complete response (pCR) rates, and disease-free survival (DFS) compared to chemotherapy alone [2]. Thus, in patients

\section{KARGER \\ Fax +497614520714 \\ Information@Karger.de}

www.karger.com (c) 2011 S. Karger GmbH, Freibur

$1661-3791 / 11 / 0066-0419 \$ 38.00 / 0$

Accessible online at:

www.karger.com/brc
Prof. Dr. med. Jens Huober

Kantonsspital St. Gallen

Brustzentrum

9007 St. Gallen, Switzerland

Tel. +41 71 494-1880, Fax -6368

jens.huober@kssg.ch 
with locally advanced or inflammatory disease with HER2 overexpression, trastuzumab should be part of the multimodal treatment. Since most of the developments in the field of neoadjuvant therapy over the last 20 years have been done in patients with operable breast cancer, this review will focus on this patient population.

\section{Randomized Trials Comparing Neoadjuvant and Adjuvant Treatment in Operable Breast Cancer}

The theory that breast cancer is a systemic rather than a local disease led to the investigation of adjuvant chemotherapy in randomized phase III trials in patients with breast cancer more than 30 years ago. 2 landmark trials by Bonnadonna et al. [3] and Fisher et al. [4] showed that adjuvant chemotherapy improved DFS and overall survival (OS). Because of the possibility that neoadjuvant chemotherapy may improve outcome by exposing micrometastases to early chemotherapy, neoadjuvant therapy was investigated in patients with primary operable disease. Since it is known from the advanced setting that neoadjuvant treatment has the ability to shrink tumors, this treatment approach may also allow for breast conserving treatment in patients who otherwise would have needed a mastectomy. The pioneer trial investigating these important issues was the B18 trial of the NSABP (National Surgical Adjuvant Breast and Bowel Project). In this study, 1,523 women with operable breast cancer were randomized to 4 cycles of AC (adriamycin, cyclophosphamide) either before or after definitive surgery. In the neoadjuvant group, $80 \%$ of the patients had a clinical complete (CR) or partial response (PR). A pCR, which was defined as the absence of malignant tumor cells at the site of the primary tumor irrespective of nodal status, was seen in $13 \%$ of the patients. In contrast to the adjuvant group, the number of patients with positive nodes was significantly lower in the neoadjuvant group (59 vs. $43 \%$; $\mathrm{p}<0.001)$. Furthermore, a higher rate of breast conserving treatment was observed with neoadjuvant treatment versus adjuvant treatment ( 67 vs. $60 \% ; p=0.002$ ). In tumors larger than $5 \mathrm{~cm}$ in diameter, the difference was more obvious in favor of the neoadjuvant approach ( 22 vs. $8 \%$ ). There were no significant differences in DFS and OS, even though updated results with follow-up exceeding 15 years indicated a trend in favor of neoadjuvant treatment in women younger than 50 years for DFS (hazard ratio (HR) 0.85; $\mathrm{p}=0.053$ ). There were also no significant differences in ipsilateral breast cancer relapse rates between the neoadjuvant and adjuvant group (7.9 vs. 5.8\%; $\mathrm{p}=0.23$ ) [5-7]. 2 further trials [8,9], one of which used not only anthracyclines but an anthracycline/ taxane-containing regimen, confirmed the findings of the B18 trial (table 1). Similar results were also reported in a metaanalysis mainly including older trials with regimens not commonly used today [10].

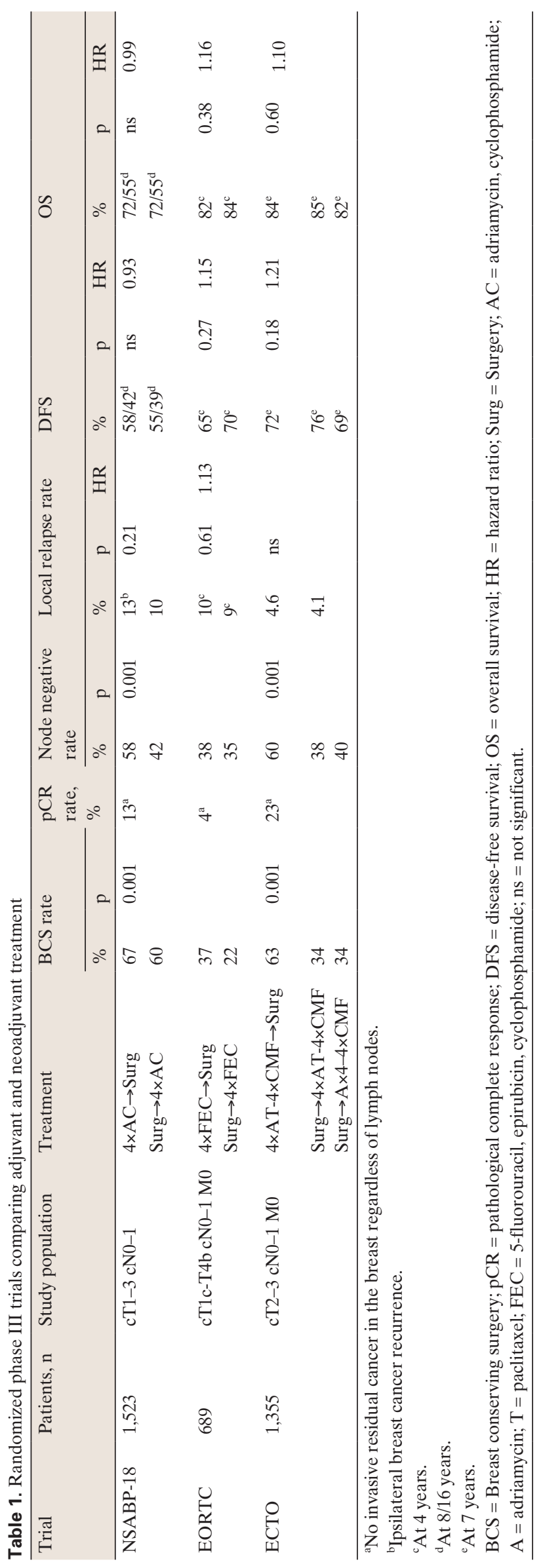




\section{Integration of Taxanes and Investigation of Alternative Schedules}

The more recent neoadjuvant trials have focused on the addition of taxanes and alternative schedules such as dose dense chemotherapy. To study the role of taxanes in the neoadjuvant setting, the NSABP-27 trial randomized 2,411 women with operable breast cancer (excluding patients with $\mathrm{T} 4$ tumors) to 4 cycles of $\mathrm{AC}$ alone, 4 cycles of AC followed by 4 cycles of docetaxel (Doc) before surgery, and in the third arm to 4 cycles of neoadjuvant AC followed by 4 cycles of adjuvant Doc after surgery. The addition of Doc preoperatively to AC increased significantly the clinical CR rate (40 vs. $64 \%$; p > 0.001), the pCR rate ( 14 vs. $26 \%$; p > 0.001), and the proportion of patients with negative nodes (51 vs. $58 \%$; p > 0.001) compared to 4 cycles of AC. However, despite the pCR rate being almost doubled by the addition of taxanes to AC preoperatively, the study did not demonstrate a significant improvement in outcome in terms of DFS and OS [11, 12].

A dose-dense schedule was investigated in 2 AGO (German Gynecological Oncology Working Group) trials. In the first trial, 668 patients with large primary tumors $(>3 \mathrm{~cm})$ including inflammatory disease were randomized to 3 cycles of epirubicin $\left(150 \mathrm{mg} / \mathrm{m}^{2}\right)$ followed by 3 cycles paclitaxel $\left(250 \mathrm{mg} / \mathrm{m}^{2}\right)$ every 2 weeks given with granulocyte colonystimulating factor (GCSF) support, or to 4 cycles of paclitaxel $\left(175 \mathrm{mg} / \mathrm{m}^{2}\right)$ in combination with epirubicin $\left(90 \mathrm{mg} / \mathrm{m}^{2}\right)$. All patients received 3 cycles $\mathrm{CMF}$ (cyclophosphamide, methotrexate, fluorouracil) as adjuvant treatment following surgery. Dose-dense chemotherapy significantly improved pCR rate (18 vs. $10 \%$ ), and in addition DFS (HR 0.71, $\mathrm{p}=0.001)$ and OS (HR 0.83, p = 0.041), compared to conventional-dosed treatment. Dose-dense treatment was associated with significantly more non-hematologic toxicities, anemia, and thrombocytopenia [13]. In the PREPARE trial, 733 patients with breast cancer were randomized to either 4 cycles of EC (epirubicin, cyclophosphamide) in standard doses followed by 4 cycles of paclitaxel $\left(175 \mathrm{mg} / \mathrm{m}^{2}\right)$ every 3 weeks, or to dose-dense epirubicin followed by paclitaxel with doses as reported in the previous trial followed by 3 cycles of CMF preoperatively. Patients were further randomized to simultaneous darbepoetin alfa or control. Pathologic response rates were significantly higher with the dose-dense regimen (ypT0/ pTisypN0 21 vs. 14\%), however, the outcome in terms of 3-year DFS (75.8 vs. $78.8 \%$ ) and OS (88.4 vs. $91.5 \%)$ was not significantly different compared to the standard-dose regimen, which might be explained by the sample size of the study relative to the effect size. Interestingly, 3-year DFS (74.3 vs. $80 \%$; HR 1.31, p = 0.061) and OS (88 vs. 91.8\%; HR 1.33, p = $0.139)$ were to the disadvantage of the darbopoetin arm. Even though these differences were not statistically significant, the use of darbopoetin may negatively influence outcome $[14,15]$. In the GeparDuo trial [16] of the German Breast Group (GBG), 913 patients were randomized to an 8-week dose- dense regimen with doxorubicin $\left(50 \mathrm{mg} / \mathrm{m}^{2}\right)$ plus Doc $(75 \mathrm{mg} /$ $\mathrm{m}^{2}$ ) given every 2 weeks with GCSF support, or to a 24-week sequential schedule with AC followed by Doc (AC-Doc) according to one arm of the NSABP B-27 trial. The pCR rate was significantly higher in the sequential than in the 8 -week dose-dense arm (14.3 vs. $10.6 \%$ ). The rates of breast conserving surgery were $63.4 \%$ in the AC-Doc and $58.1 \%$ in the dose-dense group $(\mathrm{p}=0.05)$.

\section{Pathological Assessment}

Previous and more recent trials have shown that patients achieving a pCR have a more favorable outcome than those without a $\mathrm{pCR}$, and attainment of a pCR has emerged as the primary endpoint in most of the neoadjuvant trials [17]. However, despite this strong evidence of the predictive value of a $\mathrm{pCR}$, the definitions of pCR vary across clinical trials, and there is no accepted consensus as to what definition should be used. The most stringent definition of pCR, which is used by the $\mathrm{GBG}$, is no invasive or non-invasive residual disease in the breast or nodes [18]. No invasive residual disease in the breast and nodes but non-invasive breast residuals allowed has been used by the MD Anderson, BIG, and ABCSG study groups $[5,19,20]$. The less restrictive definition from the NSABP group allows non-invasive breast residuals and infiltrated lymph nodes and requires only absence of invasive residual disease in the breast. The predictive power of the parameter pCR in terms of outcome was seen in various trials with different definitions of pCR. However, in a meta-analysis of 7 neoadjuvant German trials with 6,377 patients all of which were treated with anthracylines and taxanes \pm trastuzumab, DFS and OS were significantly better when the strict definition was used compared to the other definitions [21]. Thus, with this definition (ypT0 ypN0), the most favorable group with the highest sensitivity to treatment could be selected. It is widely accepted that the presence of nodal involvement after neoadjuvant chemotherapy predicts a poorer prognosis $[11,12]$ and should be considered as residual disease when defining pCR. However, the influence of the presence or absence of residual carcinoma in situ after preoperative therapy on outcome is a matter of controversy since data of the German meta-analysis are in contrast to the results of investigators from the MD Anderson. In their analysis of 2,302 neoadjuvantly treated patients, no difference in DFS or OS was seen between ypT0 ypN0 and ypTis ypN0 patients [22]. However, one should consider that in the German analysis 309 and in the MD Anderson 78 patients had only in situ residuals at the time of surgery, so that the statistical power to detect prognostic differences for the definitions was much less in the American cohort. Another factor which may explain the different results is the pathological workup of the resected specimens. Pathological assessment in a single institution as in the MD Anderson study may have been more standardized 
and may have more precisely located in situ disease only compared to a multicenter trial with pathological assessment in every single center with a less standardized procedure.

Another area of controversy is the acceptance of the pCR as a surrogate for survival. Not all patients who achieve a pCR remain recurrence-free, and not all patients who do not respond well to preoperative treatment relapse. Furthermore, even though the pCR rates in the NSABP-B27 trial were doubled by adding 4 cycles of a taxane to $\mathrm{AC}$, this did not result in a significant improvement in outcome [11, 12]. This observation raises the issue to what extent the short-term $\mathrm{pCR}$ rate is a surrogate for long-term outcome. Breast cancer is a heterogenous disease, and it is now widely accepted that the disease is divided into several subtypes with different biological behaviors [23]. These different subtypes include the luminal A tumors which are hormone receptor (HR)-positive and HER2-negative with low proliferation, the luminal B tumors which are HR-positive but with higher proliferation and/or a poor grading or a positive HER2 status, the triple-negative tumors which are estrogen receptor-, progesterone receptor-, and HER2-negative and mostly show a high proliferation, and the HER2-positive subset. Since all these kinds of intrinsic subtypes were included in the neoadjuvant trials, this heterogeneity may have diluted the prognostic information of $\mathrm{pCR}$. In the previously described meta-analysis of 7 German neoadjuvant trials [21], the prognostic impact of pCR on DFS and OS in intrinsic breast cancer subgroups was investigated. Indeed, pCR was not a suitable surrogate endpoint in the low proliferating, highly endocrine-sensitive tumors (luminal A subtype) which also showed a very low pCR rate, and in the HR-positive, HER2-positive (luminal B/HER2+) subtypes. In contrast, in the HR-negative tumors, both HER2-positive and -negative (triple-negative, non-luminal HER2+ subtypes), and in the HR-positive poorly graded tumors (luminal B/ HER2-), pCR was significantly associated with improved DFS and OS.

\section{Who Should be Treated with Neoadjuvant Chemotherapy}

In locally advanced and inflammatory breast cancer, neoadjuvant chemotherapy as part of a multimodal approach is standard of care. In patients with operable disease, neoadjuvant chemotherapy is a valid treatment option when mastectomy seems necessary but the patient wishes breast conserving surgery; tumor shrinkage may then allow for this surgical approach. Further neoadjuvant chemotherapy may be given in all patients when the same chemotherapy is indicated as adjuvant treatment [24]. Patients who have a high likelihood of achieving a pCR with neoadjuvant chemotherapy may be especially considered for neoadjuvant treatment. In an analysis of the GeparTrio trial, independent factors significantly associated with a pCR were age below 40 years, grade 3 tu-
Table 2. Summary neoadjuvant chemotherapy

\begin{tabular}{l} 
Neoadjuvant chemotherapy \\
Results in similar disease-free survival (DFS) and overall survival (OS) \\
as adjuvant treatment \\
Results in similar locoregional control as adjuvant treatment \\
Results in a higher rate of breast conserving surgery \\
Can be offered when adjuvant chemotherapy is indicated \\
\hline Predictors of response to neoadjuvant chemotherapy are negative \\
hormone receptors, triple-negative receptors, poor grading, \\
non-lobular histology, clinical midterm response, and young age \\
The likelihood of a therapy response (pathologic complete response, \\
pCR) and the long-term outcome (DFS, OS) vary in different \\
molecular subsets \\
pCR may only be an appropriate surrogate marker for DFS and OS \\
in special molecular subtypes of breast cancer \\
No invasive or non-invasive residuals in the breast and nodes (yPT0 \\
ypN0) is the best predictor for an excellent outcome and should \\
be used as the definition of pCR \\
\hline Neoadjuvant treatment necessitates a multidisciplinary approach to \\
achieve optimal results \\
Anthracycline/taxane-based regimens were the most effective \\
treatments in terms of pCR and should be given over 4-6 months \\
Anti-HER2 therapy in HER2-positive disease (currently trastuzumab \\
outside clinical trials) should be part of the neoadjuvant treatment \\
Other targeted approaches like bevacizumab are not standard of care \\
and should be limited to clinical trials as long as no long-term out- \\
come data are available
\end{tabular}

mors, negative HRs, and a non-lobular histology. Patients with HR-positive disease had a probability of achieving a pCR of above $10 \%$ only with grade 3 tumors [25]. These data are in line with several other reports showing similar results $[26,27]$. In HER2-overexpressing tumors, pCR rates are as high as $50 \%$ when trastuzumab is added to neoadjuvant chemotherapy. Table 2 gives an overview of the various aspects of neoadjuvant therapy.

\section{Chemotherapy Response as a Guide to Subsequent Treatment}

A unique aspect of preoperative therapy is the opportunity to monitor tumor response to treatment and to tailor individual treatment based on response. The pathological response can only be assessed after several months at the end of neoadjuvant treatment when surgery has been performed. Therefore, it is of special interest to identify predictors which give information about treatment response early in the course of treatment. However, it is even more important to know whether the switch to a non-crossresistant treatment after lack of an initial response to standard chemotherapy is associated with better outcome. We know from the GeparDuo and GeparTrio trials that early response as defined by clinical examination or ultrasound was associated with higher pCR rates at surgery [28-30]. Moreover, data from the GeparTrio trial suggest that most of the factors predictive of a pCR at surgery, such as HR-negative status, poor grading, and young 
age, were also predictors for early midterm response. Tumors with a non-lobular histology and non-T4 tumors were the only ones exclusively associated with a pCR at surgery [25].

The GeparTrio trial, however, also investigated the concept of interim response-adapted neoadjuvant chemotherapy. 2,072 patients with operable or locally advanced breast cancer were treated with 2 cycles of TAC (Doc, doxorubicin, cyclophosphamide) before an interim response assessment. Responders were randomized to additional TAC $\times 4(\mathrm{n}=704)$ or TAC $\times 6(n=686)$, and non-responders to TAC $\times 4(\mathrm{n}=321)$ or NX (vinorelbine, capecitabine) $\times 4(\mathrm{n}=301)$. None of the HER2+ patients received trastuzumab. Regarding short-term efficacy, TAC $\times 8$ did not significantly increase the $\mathrm{pCR}$ rate in the responder population compared to TAC $\times 6$ (23.5 vs. $21 \%)$. In the non-responder group, similar efficacy was observed, pCR rates were low in both randomization arms and switching to a non-cross resistant regimen resulted in similar pCR rates (6.0 vs. 5.3\%) compared to continuing with 4 more cycles TAC. In a second analysis after a median follow-up of 62 months, long-term outcome was investigated and results will be released soon.

\section{Integration of Targeted Therapies in Neoadjuvant Treatment}

Trastuzumab is an established treatment for HER2-positive breast cancer and has also been widely investigated in the neoadjuvant setting. One of the first trials was conducted at the MD Anderson Cancer Center, and patients with stage II and IIIa HER2-overexpressing tumors randomized to 4 cycles of paclitaxel followed by 4 cycles of FEC (fluorouracil, epirubicin, cyclophosphamide) with or without trastuzumab [31]. After treating 42 patients, the study was stopped prematurely due to the remarkably high pCR rate in the trastuzumab arm ( 65 vs. $25 \%$; $p=0.02$ ). Cardiac events were not higher in the trastuzumab group even though it was combined with anthracyclines. In the phase III GeparQuattro study, 1,510 patients received 4 cycles of EC and were randomly assigned to 4 cycles of Doc, or 4 cycles of Doc in combination with capecitabine, or 4 cycles of Doc followed by 4 cycles of capecitabine. Women with HER2-positive tumors $(n=445)$ received trastuzumab concomitantly with all neoadjuvant chemotherapy before surgery. The pCR rate (ypT0 ypNo) in these women with HER2-positive tumors was $31.7 \%$ compared to $15.7 \%$ in the HER2-negative reference group $(\mathrm{n}=1,050)$. The addition of trastuzumab resulted in more febrile neutropenia and conjunctivitis, but with a comparable short-term cardiac toxicity profile as the reference group [32]. These data confirm the cardiac safety of the smaller MD Anderson trial group both using epirubicin instead of doxorubicin in combination with trastuzumab. In the multicenter phase II Techno trial lead by the AGO, 217 patients with HER2-positive primary breast cancer were treated with 4 cycles of EC every 3 weeks fol- lowed by 4 cycles of paclitaxel $\left(175 \mathrm{mg} / \mathrm{m}^{2}\right)$ in combination with trastuzumab every 3 weeks followed by surgery [33]. All patients completed trastuzumab after surgery (1 year). The pCR rate was $39 \%$, and achievement of a pCR was predictive of a superior prognosis (3-year DFS with or without pCR 88 vs. $73 \%$, respectively; $p=0.01$ ) Recently, first data of the NeoALTTO [34] trial were reported. This study is comparing the efficacy of neoadjuvant lapatinib (a dual tyrosine kinase inhibitor of both HER1 and HER2) plus paclitaxel versus trastuzumab plus paclitaxel versus concomitant lapatinib and trastuzumab plus paclitaxel given as neoadjuvant treatment over 12 weeks in 455 patients with HER2-overexpressing primary breast cancer. The pCR was 25 and $30 \%$ with lapatinib or trastuzumab, respectively (without statistically significant differences; $\mathrm{p}=0.34$ ) and almost doubled (pCR 51\%) when both agents were added to paclitaxel. All 3 treatment regimens achieved a higher pCR rate in HR-negative $(34,37$, $61 \%$, respectively) compared to HR-positive $(16,23,46 \%$, respectively) tumors. In addition to the NeoALTTO trial, the adjuvant ALTTO trial was recently fully recruited. This trial has a similar design as NeoALTTO and gives the opportunity to see if the short-term superiority of the dual HER2 blockade wit trastuzumab and lapatinib will also translate in a longterm DFS and OS advantage. The NeoSphere trial is another neoadjuvant trial investigating the dual HER2 blockade, however, with pertuzumab - a different combination partner for trastuzumab. Interestingly, this trial also investigates the chemotherapy-free combination of these 2 anti-HER2 agents in the neoadjuvant setting [35]. Pertuzumab is a recombinant humanized monoclonal antibody and prevents dimerization of HER2 with other HER receptors (HER1/3/4). Pertuzumab binds to a different HER2 epitope than trastuzumab and has shown activity in trastuzumab-resistant disease [36]. In the NeoSphere trial, 417 patients with HER2-overexpressing breast cancer were randomized to 12 weeks Doc plus trastuzumab, or Doc plus trastuzumab and pertuzumab, or trastuzumab with pertuzumab and Doc plus pertuzumab. pCR rates were $29,46,17$, and $24 \%$, respectively. Similar to NeoALTTO, pCR rates were distinctively higher in HR-negative $(37,63,29,30 \%$, respectively) compared to HR-positive $(20,26,6,17 \%$, respectively) tumors. In the GeparQuinto trial, 615 HER2-positive patients were treated with EC and Doc each given for 4 cycles, and randomly assigned to trastuzumab or lapatinib given for the entire 24 -week treatment period until surgery. Trastuzumab was continued after surgery for 6 or 12 months in the trastuzumab and lapatinib arms, respectively [37]. In this trial, the pCR rate was significantly higher with trastuzumab than with lapatinib (31 vs. $22 \%$; $\mathrm{p}<0.05)$. Compliance of EC-Doc with lapatinib was lower than with trastuzumab and may explain the lower pCR rate of lapatinib. Further treatment duration in the NeoALTTO was half of that of the GeparQuinto trial. Preliminary results of small phase II studies combining 2 anti-HER2 agents with a long chemotherapy regimen reported pCR rates of 74\% [38]. 
Table 3. Neoadjuvant trials in HER2-positive primary breast cancer

\begin{tabular}{|c|c|c|c|c|c|c|c|}
\hline & \multicolumn{7}{|l|}{ Trial } \\
\hline & NeoSphere & NeoALTTO & GeparQuinto & GeparQuattro & Techno & MD Anderson & NOAH \\
\hline CHT & Doc & $\mathrm{Pac}$ & EC-Doc & EC-Doc \pm Cap & EC-Pac ${ }^{b}$ & Pac-FEC & APac-Pac-CMF \\
\hline Duration, weeks & 12 & $12+6^{a}$ & 24 & $24 / 36$ & 24 & 24 & 33 \\
\hline \multicolumn{8}{|l|}{$\mathrm{CHT}+\mathrm{Tra}$} \\
\hline $\mathrm{n}$ & 107 & 149 & 309 & 445 & 217 & 23 & 117 \\
\hline $\mathrm{pCR}^{\mathrm{c}}$ rate, $\%$ & 21.5 & 27.6 & 44.6 & 40.0 & 39.0 & 65.2 & 38.0 \\
\hline \multicolumn{8}{|c|}{$\mathrm{CHT}+2$ anti-HER 2 agents } \\
\hline Agents & Tra + Per & Tra + Lap & & & & & \\
\hline $\mathrm{n}$ & 107 & 152 & & & & & \\
\hline pCR rate, $\%$ & 39.3 & 46.9 & & & & & \\
\hline
\end{tabular}

\footnotetext{
${ }^{a}$ Treatment started with 6 weeks anti-HER2 therapy alone followed by the addition of paclitaxel for 12 weeks.

${ }^{\mathrm{b}}$ Tra only added to Pac.

cpCR defined as ypT0/pTisypN0.

$\mathrm{CHT}=$ Chemotherapy; Doc $=$ docetaxel $; \mathrm{Pac}=$ paclitaxel $; \mathrm{EC}=$ epirubicine, cyclophospamide $; \mathrm{Cap}=$ capecitabine;

$\mathrm{FEC}=$ 5-fluorouracil, epirubicine, cyclophospamide; $\mathrm{A}=$ adriamycin; Tra = trastuzumab; Per = pertuzumab; Lap = lapatinib;

$\mathrm{CMF}=$ cyclophosphamide, methotrexate, fluorouracil .
}

Table 3 summarizes neoadjuvant trials in patients with HER2positive breast cancer.

In the HER2-negative part of the GeparQuinto trial, the concept of anti-angiogenesis was investigated [39]. In total, 1,948 patients were randomized to receive 4 cycles of EC followed by 4 cycles of Doc each every 3 weeks with or without concomitant bevazicumab $15 \mathrm{mg} / \mathrm{kg}$ added to chemotherapy. Patients not clinically responding to $\mathrm{EC} \pm$ bevazicumab were taken off the initial treatment plan and were re-randomized to weekly paclitaxel \pm everolimus (RAD 001). Whereas no effect of bevazicumab in HR-positive patients was seen, bevazicumab could increase the pCR rate in triple-negative tumors by an odds ratio of 1.67 [40]. Toxicity increased especially when bevazicumab was added to Doc (febrile neutropenia and mucositis). Conflicting results were observed in the NSABP B40 trial. In this study, patients received 1 of 3 taxane-based regimens preoperatively (Doc $\times 4$ vs. Doc $\times 4$ plus capecitabine vs. Doc $\times 4$ plus gemcitabine followed by $\mathrm{AC} \times 4$ ) with or without bevazicumab given every 3 weeks. The addition of bevazicumab to chemotherapy improved pCR rates (28.4 vs. $34.5 \%$; $=0.027)$ whereas the addition of capecitabine or gemcitabine did not influence response to treatment. The effect of bevazicumab was predominantly seen in the HR-positive subset with minimal effect in the HR-negative subset [41].

\section{Conclusions}

Several randomized trials showed that DFS and OS in patients with operable breast cancer was the same following neoadjuvant chemotherapy compared to adjuvant treatment. The rate of patients with breast conserving surgery however could be increased when neoadjuvant chemotherapy was given. Thus, neoadjuvant chemotherapy can now be offered as a valid treatment option to patients with operable breast cancer irrespective of tumor size when adjuvant chemotherapy is indicated. Important goals for the future are to identify predictors for early response and to tailor neoadjuvant chemotherapy according to midterm response. Further aims are to better integrate surgery in the multimodal concept of the neoadjuvant treatment. In this context, important questions are how to best include the sentinel node technique and if there are patients with clinical CR, who do not need surgery of the breast and axilla. The neoadjuvant setting gives the unique opportunity to get insights in breast cancer biology and to evaluate not only new therapies but to find predictive factors for better individualization of the treatment.

\section{Disclosure Statement}

J.H. is member of advisory boards for Sanofi-Aventis, Roche, BMS, Amgen, and Novartis, has received honoraria from Sanofi-Aventis, Roche, and Novartis and has received research grants from GSK.

G.v.M. has received research grants from Sanofi-Aventis, Roche, Amgen, GSK, Novartis, and BMS. 


\section{References}

1 Sinclair S, Swain SM: Primary systemic chemotherapy for inflammatory breast cancer. Cancer 2010;116(suppl):2821-8.

2 Gianni L, Eiermann W, Semiglazov V, Manikhas A, Lluch A, Tjulandin S, Zambetti M, Vazquez F, Byakhow M, Lichinitser M, Climent MA, Ciruelos E, Ojeda B, Mansutti M, Bozhok A, Baronio R, Feyereislova A, Barton C, Valagussa P, Baselga J: Neoadjuvant chemotherapy with trastuzumab followed by adjuvant trastuzumab versus neoadjuvant chemotherapy alone, in patients with HER2-positive locally advanced breast cancer (the NOAH trial): a randomised controlled superiority trial with a parallel HER2-negative cohort. Lancet 2010;375:377-84.

$>3$ Bonadonna G, Valagussa P, Moliterni A, Zambetti M, Brambilla C: Adjuvant cyclophosphamide, methotrexate, and fluorouracil in node-positive breast cancer: the results of 20 years of followup. N Engl J Med 1995;332:901-6.

4 Fisher B, Carbone P, Economou SG, Frelick R, Glass A, Lerner H, Redmond C, Zelen M, Brand P, Katrych DL, Wolmark N, Fisher ER: L-phenylalanine mustard (L-PAM) in the management of primary breast cancer - a report of early findings. N Engl J Med 1975;292:117-22.

$\checkmark 5$ Fisher B, Brown A, Mamounas E, Wieand S, Robidoux A, Margolese RG, Cruz AB Jr, Fisher ER, Wickerham DL, Wolmark N, DeCillis A, Hoehn JL, Lees AW, Dimitrov NV: Effect of preoperative chemotherapy on local-regional disease in women with operable breast cancer: findings from National Surgical Adjuvant Breast and Bowel Project B-18. J Clin Oncol 1997;15:2483-93.

6 Fisher B, Bryant J, Wolmark N, Mamounas E, Brown A, Fisher ER, Wickerham DL, Begovic M, DeCillis A, Robidoux A, Margolese RG, Cruz AB Jr, Hoehn JL, Lees AW, Dimitrov NV, Bear HD Effect of preoperative chemotherapy on the outcome of women with operable breast cancer. J Clin Oncol 1998;16:2672-85.

7 Rastogi P, Anderson SJ, Bear HD, Geyer CE, Kahlenberg MS, Robidoux A, Margolese RG, Hoehn JL, Vogel VG, Dakhil SR, Tamkus D, King KM, Pajon ER, Wright MJ, Robert J, Paik S, Mamounas EP, Wolmark N: Preoperative chemotherapy: updates of National Surgical Adjuvant Breast and Bowel Project Protocols B-18 and B-27. J Clin Oncol 2008;26:778-85.

$>8$ Gianni L, Baselga J, Eiermann W, Porta VG, Semiglazov V, Lluch A, Zambetti M, Sabadell D, Raab G, Cussac AL, Bozhok A, Martinez-Agulló A, Greco M, Byakhov M, Lopez JJ, Mansutti M, Valagussa P, Bonadonna G: Phase III trial evaluating the addition of paclitaxel to doxorubicin followed by cyclophosphamide, methotrexate, and fluorouracil, as adjuvant or primary systemic therapy: European Cooperative Trial in Operable Breast Cancer. J Clin Oncol 2009;27:2474-81.

$\checkmark 9$ Van der Hage JA, van de Velde CJ, Julien JP, Tubiana-Hulin M, Vandervelden C, Duchateau L: Preoperative chemotherapy in primary operable breast cancer: results from the European Organization for Research and Treatment of Cancer trial 10902. J Clin Oncol 2001;19:4224-37.

10 Mauri D, Pavlidis N, Ioannidis JP: Neoadjuvant versus adjuvant systemic treatment in breast cancer: a meta-analysis. J Natl Cancer Inst 2005; 97:188-94.

11 Bear HD, Anderson S, Brown A, Smith R, Mamounas EP, Fisher B, Margolese R, Theoret H, Soran A, Wickerham DL, Wolmark N; National
Surgical Adjuvant Breast and Bowel Project Protocol B-27: The effect on tumor response of adding sequential preoperative docetaxel to preoperative doxorubicin and cyclophosphamide: preliminary results from National Surgical Adjuvant Breast and Bowel Project Protocol B-27.J Clin Oncol 2003;21:4165-74.

12 Bear HD, Anderson S, Smith RE, Geyer CE Jr, Mamounas EP, Fisher B, Brown AM, Robidoux A, Margolese R, Kahlenberg MS, Paik S, Soran A, Wickerham DL, Wolmark N: Sequential preoperative or postoperative docetaxel added to preoperative doxorubicin plus cyclophosphamide for operable breast cancer:National Surgical Adjuvant Breast and Bowel Project Protocol B-27. J Clin Oncol 2006;24:2019-27.

13 Untch M, Möbus V, Kuhn W, Muck BR, Thomssen C, Bauerfeind I, Harbeck N, Werner C, Lebeau A, Schneeweiss A, Kahlert S, von Koch F, Petry KU, Wallwiener D, Kreienberg R, Albert US, Lück HJ, Hinke A, Jänicke F, Konecny GE: Intensive dose-dense compared with conventionally scheduled preoperative chemotherapy for high-risk primary breast cancer. J Clin Oncol 2009; 27:2938-45.

14 Untch M, Fasching PA, Konecny GE, von Koch F, Conrad U, Fett W, Kurzeder C, Lück HJ, Stickeler E, Urbaczyk H, Liedtke B, Salat C, Harbeck N, Müller V, Schmidt M, Hasmüller S, Lenhard M, Schuster T, Nekljudova V, Lebeau A, Loibl S, von Minckwitz G; on behalf of the Arbeitsgemeinschaft Gynäkologische Onkologie PREPARE investigators: PREPARE trial: a randomized phase III trial comparing preoperative, dose-dense, dose-intensified chemotherapy with epirubicin, paclitaxel and CMF versus a standarddosed epirubicin/cyclophosphamide followed by paclitaxel $(+/-)$ darbepoetin alfa in primary breast cancer - results at the time of surgery. Ann Oncol 2011;22:1988-98.

15 Untch M, von Minckwitz G, Konecny GE, Conrad U, Fett W, Kurzeder C, Lück HJ, Stickeler E, Urbaczyk H, Liedtke B, Beckmann MW, Salat C, Harbeck N, Müller V, Schmidt M, Hasmüller S, Lenhard M, Nekljudova V, Lebeau A, Loibl S, Fasching PA; on behalf of the Arbeitsgemeinschaft Gynäkologische Onkologie (AGO) PREPARE (Preoperative Epirubicin, Paclitaxel, Darbepoetin) investigators: PREPARE trial: a randomized phase III trial comparing preoperative, dose-dense, dose-intensified chemotherapy with epirubicin, paclitaxel, and CMF versus a standard-dosed epirubicin-cyclophosphamide followed by paclitaxel with or without darbepoetin alfa in primary breast cancer - outcome on prognosis. Ann Oncol 2011;22:1999-2006.

16 Von Minckwitz G, Raab G, Caputo A, Schütte M, Hilfrich J, Blohmer JU, Gerber B, Costa SD, Merkle E, Eidtmann H, Lampe D, Jackisch C, du Bois A, Kaufmann M: Doxorubicin with cyclophosphamide followed by docetaxel every 21 days compared with doxorubicin and docetaxel every 14 days as preoperative treatment in operable breast cancer: the GEPARDUO study of the German Breast Group. J Clin Oncol 2005;23:2676-85.

17 Kaufmann M, Hortobagyi GN, Goldhirsch A, Scholl S, Makris A, Valagussa P, Blohmer JU, Eiermann W, Jackesz R, Jonat W, Lebeau A, Loibl S, Miller W, Seeber S, Semiglazov V, Smith R, Souchon R, Stearns V, Untch M, von Minckwitz G: Recommendations from an international expert panel on the use of neoadjuvant (primary) systemic treatment of operable breast cancer: an update. J Clin Oncol 2006;24:1940-9.

18 Sinn HP, Schmid H, Junkermann H, Huober J, Leppien G, Kaufmann M, Bastert G, Otto HF: Histologic regression of breast cancer after primary (neoadjuvant) chemotherapy. Geburtshilfe Frauenheilkd 1994;54:552-8.

19 Green MC, Buzdar AU, Smith T, Ibrahim NK, Valero V, Rosales MF, Cristofanilli M, Booser DJ, Pusztai L, Rivera E, Theriault RL, Carter C, Frye D, Hunt KK, Symmans WF, Strom EA Sahin AA, Sikov W, Hortobagyi GN: Weekly paclitaxel improves pathologic complete remission in operable breast cancer when compared with paclitaxel once every 3 weeks. J Clin Oncol 2005;23:5983-92.

20 Steger GG, Greil R, Jakesz R: A randomised phase 3 study comparing epirubicin, docetaxel and capecitabine (EDC) to epirubicin and docetaxel (ED) as neoadjuvant treatment: the first results of ABCSG-24. European J Cancer 2009;7(suppl):abstr 3.

21 Von Minckwitz G, Kaufmann M, Kuemmel S, Fasching PA, Eiermann W, Blohmer JU, Costa SD, Hilfrich J, Jackisch C, Gerber B, Du Bois A, Huober JB, Hanusch CA, Konecny GE, Fett W, Stickeler E, Harbeck N, Mehta K, Loibl S, Untch M: Correlation of various pathologic complete response ( $\mathrm{pCR}$ ) definitions with long-term outcome and the prognostic value of $\mathrm{PCR}$ in various breast cancer subtypes: results from the German neoadjuvant meta-analysis. J Clin Oncol 2011;29(suppl):abstr 1028.

22 Mazouni C, Peintinger F, Wan-Kau S, Andre F, Gonzalez-Angulo AM, Symmans WF, MericBernstam F, Valero V, Hortobagyi GN, Pusztai L: Residual ductal carcinoma in situ in patients with complete eradication of invasive breast cancer after neoadjuvant chemotherapy does not adversely affect patient outcome. J Clin Oncol 2007;25:2650-5.

23 Prat A, Perou CM: Deconstructing the molecular portraits of breast cancer. Mol Oncol 2011;5:5-23.

24 Goldhirsch A, Ingle JN, Gelber RD, Coates AS, Thürlimann B, Senn HJ; Panel members: Thresholds for therapies: highlights of the St. Gallen International Expert Consensus on the primary therapy of early breast cancer 2009. Ann Oncol 2009;20:1319-29.

25 Huober J, von Minckwitz G, Denkert C, Tesch H, Weiss E, Zahm DM, Belau A, Khandan F, Hauschild M, Thomssen C, Högel B, DarbEsfahani S, Mehta K, Loibl S: Effect of neoadjuvant anthracycline-taxane-based chemotherapy in different biological breast cancer phenotypes: overall results from the GeparTrio study. Breast Cancer Res Treat 2010;124:133-40.

26 Colleoni M, Bagnardi V, Rotmensz N, Gelber RD Viale G, Pruneri G, Veronesi P, Torrisi R, Cardillo A, Montagna E, Campagnoli E, Luini A, Intra M, Galimberti V, Scarano E, Peruzzotti G, Goldhirsch A: Increasing steroid hormone receptors expression defines breast cancer subtypes non responsive to preoperative chemotherapy. Breast Cancer Res Treat 2009;116:359-69.

27 Gralow JR, Burstein HJ, Wood W, Hortobagyi GN, Gianni L, von Minckwitz G, Buzdar AU, Smith IE, Symmans WF, Singh B, Winer EP: Preoperative therapy in invasive breast cancer: pathologic assessment and systemic therapy issues in operable disease. J Clin Oncol 2008;26:814-9.

28 Von Minckwitz G, Costa SD, Raab G, Blohmer JU, Eidtmann H, Hilfrich J, Merkle E, Jackisch C, 
Gademann G, Tulusan AH, Eiermann W, Graf E, Kaufmann M; German Preoperative AdriamycinDocetaxel and German Adjuvant Breast Cancer Study Groups: Dose-dense doxorubicin, docetaxel, and granulocyte colony-stimulating factor support with or without tamoxifen as preoperative therapy in patients with operable carcinoma of the breast: a randomized, controlled, open phase IIb study. J Clin Oncol 2001;19:3506-15.

29 Von Minckwitz G, Kümmel S, Vogel P, Hanusch C, Eidtmann H, Hilfrich J, Gerber B, Huober J, Costa SD, Jackisch C, Loibl S, Mehta K, Kaufmann M; German Breast Group: Neoadjuvant vinorelbine-capecitabine versus docetaxel-doxorubicin-cyclophosphamide in early nonresponsive breast cancer: phase III randomized GeparTrio trial. J Natl Cancer Inst 2008;100:542-51.

30 Von Minckwitz G, Kümmel S, Vogel P, Hanusch C, Eidtmann H, Hilfrich J, Gerber B, Huober J, Costa SD, Jackisch C, Loibl S, Mehta K, Kaufmann M; German Breast Group: Intensified neoadjuvant chemotherapy in early-responding breast cancer: phase III randomized GeparTrio study. J Natl Cancer Inst 2008;100:552-62.

-31 Buzdar AU, Ibrahim NK, Francis D, Booser DJ, Thomas ES, Theriault RL, Pusztai L, Green MC, Arun BK, Giordano SH, Cristofanilli M, Frye DK, Smith TL, Hunt KK, Singletary SE, Sahin AA, Ewer MS, Buchholz TA, Berry D, Hortobagyi GN: Significantly higher pathologic complete remission rate after neoadjuvant therapy with trastuzumab, paclitaxel, and epirubicin chemotherapy: results of a randomized trial in human epidermal growth factor receptor 2-positive operable breast cancer. J Clin Oncol 2005;23:3676-85.

32 Untch M, Rezai M, Loibl S, Fasching PA, Huober J, Tesch H, Bauerfeind I, Hilfrich J, Eidtmann H, Gerber B, Hanusch C, Kühn T, du Bois A, Blohmer JU, Thomssen C, Dan Costa S, Jackisch C, Kaufmann M, Mehta K, von Minckwitz G: Neoadjuvant treatment with trastuzumab in HER2-positive breast cancer: results from the GeparQuattro study. J Clin Oncol 2010;28:2024-31.
33 Untch M, Fasching PA, Konecny GE, Hasmüller S, Lebeau A, Kreienberg R, Camara O, Müller V, du Bois A, Kühn T, Stickeler E, Harbeck N, Höss C, Kahlert S, Beck T, Fett W, Mehta KM, von Minckwitz G, Loibl S: Pathologic complete response after neoadjuvant chemotherapy plus trastuzumab predicts favorable survival in human epidermal growth factor receptor 2-overexpressing breast cancer: results from the TECHNO trial of the AGO and GBG study groups. J Clin Oncol 2011;29:3351-7.

34 Baselga J, Bradbury I, Eidtmann H, Di Cosimo S, Aura C, De Azambuja E, Gomez H, Dinh P, Fauria K, Van Dooren V, Paoletti P, Goldhirsch A, Chang T-W, Lank I, Untch N, Gelber RD, PiccartGebhart M, on Behalf of the NeoALTTO Study Team: First results of the NeoALTTO trial (BIG 01-06/EGF 106903): a phase III, randomized, open label, neoadjuvant study of lapatinib, trastuzumab, and their combination plus paclitaxel in women with HER2-positive primary breast cancer. Cancer Res 2010;70(suppl 24):abstr S3-3.

35 Gianni L, Piemkowski T, Im Y-H, Roman L, Tseng L-M, Liu MC, Lluch-Hernandez A, Semiglazov V, Szado T, Ross G: Neoadjuvant pertuzumab $(\mathrm{P})$ and trastuzumab $(\mathrm{H})$ : antitumor and safety analysis of a randomized phase II study (Neosphere). Cancer Res 2010;70(suppl 24):abstr S3-2.

36 Baselga J, Gelmon KA, Verma S, Wardley A, Conte P, Miles D, Bianchi G, Cortes J, McNally VA, Ross GA, Fumoleau P, Gianni L: Phase II trial of pertuzumab and trastuzumab in patients with human epidermal growth factor receptor 2-positive metastatic breast cancer that progressed during prior trastuzumab therapy. J Clin Oncol 2010;28:1138-44.

37 Untch M, Loibl S, Bischoff J, Eidtmann H, Kaufmann M, Blohmer J-U, Hilfrich J, Strumberg D, Fasching PA, Kreienberg R, Tesch H, Hanusch C, Gerber B, Rezai M, Jackisch C, Huober J, Kuehn T, Nekljudova V, von Minckwitz G: Lapatinib vs. trastuzumab in combination with neoadjuvant anthracyclinetaxane-based chemotherapy: primary efficacy endpoint analysis of the GEPARQUINTO study (GBG 44). Cancer Res 2010;70(suppl 24):abstr S3-1.

38 Holmes FA, Nagarwala YM, Espina VA, Liotta LA, Danso MA, Gallagher RI, McIntyre K, Osborne CRC, Mahoney JM, Florance AM, Anderson TC, O'Shaughnessy J: Correlation of molecular effects and pathologic complete response to preoperative lapatinib and trastuzumab, separately and combined prior to neoadjuvant breast cancer chemotherapy. J Clin Oncol 2011;29:45s(suppl):abstr 506.

39 Von Minckwitz G, Eidtmann H, Rezai M, Fasching PA, Tesch H, Eggemann H, Schrader J, Kittel K, Hanusch C, Kreienberg R, Solbach C, Gerber B, Jackisch C, Kunz G, Blohmer J-U, Huober J, Hauschild M, Fehm T, Loibl S, Nekljudova V, Untch M: Neoadjuvant chemotherapy with or without bevazicumab: primary efficacy endpoint analysis oft he GEPARQUINTO study (GBG44). Cancer Res 2010;70(suppl 24):abstr S4-6.

40 Gerber B, Eidtmann H, Rezai M, Fasching PA, Tesch H, Eggemann H, Schrader I, Kittel K, Hanusch CA, Kreienberg R, Solbach C, Jackisch C, Kunz G, Blohmer JU, Huober JB, Hauschild M, Loibl S, Nekljudova V, Untch M, von Minckwitz G: Neoadjuvant bevacizumab and anthracyclinetaxane-based chemotherapry in 686 triple-negative primary breast cancers: secondary endpoint analysis of the GeparQuinto study (GBG 44). J Clin Oncol 2011;29:45s(suppl):abstr 1006.

41 Baer H-D, Tang G, Rastogi P, Geyer CE, Robidoux A, Atkins JN, Baez L, Brufsky A, Mehta RS, Fehrenbacher L, Pajon ER, Senecal FM, Gaur R, Margolese RG, Adams PT, Gross HM, Swain SM, Mamounas EP, Costantino JP, Wolmark N: The effect on pCR of bevazicumab and/or antimetabolites added to standard neoadjuvant chemotherapy: NSABP protocol B-40. J Clin Oncol 2011;29:45s(suppl):abstr LBA 1005. 